\title{
Generalization of the Temperature Dependence of Some Physical Properties of High-strength Polyethylene (HDPE) Using the Method of Given Parameters
}

\author{
Shixaliyev Kerem Sefi \\ The Department of “Organic Substances and Technology of Highmolecular Compounds”, Azerbaijan Oil and Industrial University, Baku, \\ Azerbaijan
}

\author{
Email address: \\ Kerem_shixaliyev@mail.ru
}

\section{To cite this article:}

Shixaliyev Kerem Sefi. Generalization of the Temperature Dependence of Some Physical Properties of High-strength Polyethylene (HDPE) Using the Method of Given Parameters. American Journal of Chemical Engineering. Vol. 7, No. 6, 2019, pp. 130-134.

doi: 10.11648/j.ajche.20190706.11

Received: July 15, 2019; Accepted: October 19, 2019; Published: December 11, 2019

\begin{abstract}
In this paper, based on the study of HDPE by dilatometric and rheological methods in a wide range of temperatures and cooling and deformation rates, we generalized the temperature dependence of the physical properties of polyethylene using the specified parameters method. Test specimens (cylinder size: height $12 \mathrm{~mm}$, diameter $9.3 \mathrm{~mm}$ ) were obtained both in the dilatometer's test cylinder itself and in a specially designed injection mold using injection molding on a TP-125 injection molding machineThe temperatures in the experiments were added and maintained with an accuracy of 3.2. ${ }^{\circ} \mathrm{C}$. Defined by The dependence of $\rho_{-} 0 T_{-} 0 / \rho T$ (relative reduced density of the polymer) on the reduced temperature $(T-T 0)$. Test specimens (cylinder size: height $12 \mathrm{~mm}$, diameter $9.3 \mathrm{~mm}$ ) were obtained both in the dilatometer's test cylinder itself and in a specially designed injection mold using injection molding on a TP-125 injection molding machine. It was found that a reliable characteristic of the dilatometric properties of the crystallizing polymer, physically correctly and completely reflecting the features of the crystalline structure, can be obtained only in the mode of stepwise temperature changes, when at each given temperature the equilibrium value of the specific sample of the primer is fixedThus, the practical value of the dilatometric method for studying crystallizing polymers is shown, especially when comparing the results of dilatometry with the results of rheological studies.
\end{abstract}

Keywords: Dilatometry, Viscosity, Rheology, Melt, High-strength Polyethylene (HDPE), Brittleness Temperature, Parameter

\section{Introduction}

HDPE, obtained by polymerization at moderate pressures, is characterized by high linearity of macromolecules, narrow MMD and a high degree of crystallinity. These features of the chemical and physical structure of HDPE must be taken into account when studying their behavior at high temperatures (in the molten state), as well as during the processing and operation of the products obtained from them. In connection with the foregoing, these generalizations of temperature dependence on the most important physical properties of HDPE by the method of given parameters are of great scientific and practical interest.

The dilatometric properties of the polymer (temperature dependence of the specific volume) over a wide temperature range of $20-300^{\circ} \mathrm{C}$, covering the crystallized and liquid state, were studied in the mode of rather slow stepwise cooling of the polymer into a dilatometer in accordance with the procedure described by the authors [1-3].

It was found that a reliable characteristic of the dilatometric properties of a crystallizing polymer, which physically correctly and fully reflects the features of the crystalline structure, can be obtained only in a step-change mode, when the equilibrium specific volume is fixed at each given temperature polymer sample. The calculation of the primary results of dilatometric measurements was carried out according to an improved method, which allows taking into account the change in the diameter of the sample studied in 
the dilatometer, which is associated with the actual shrinkage of polyethylene.

\section{Method}

The temperature in the experiments was set and maintained with an accuracy of $0.2^{\circ} \mathrm{C}$. Researched samples of HDPE production Socar Polymer with the following main indicators:

1) The average molecular weight is 83000 , determined according to $[\eta]$ in decalin solution at $135^{\circ} \mathrm{C}$;

2) Melt flow rate - $1.4 \mathrm{~g}$ for 10 minutes, determined at $190^{\circ} \mathrm{C}$ and a load of $5 \mathrm{~kg}$.

Samples for testing (cylinder size: height $12 \pm 1 \mathrm{~mm}$, diameter $9.3 \pm 0.5 \mathrm{~mm}$ ) were obtained both in the test cylinder of the dilatometer and in a specially designed casting mold using an injection molding method on a molding machine TP-125.

In the course of dilatometry at each fixed temperature, the measurement of the temperature expansion or compression of the sample was performed with an accuracy of $0.001 \mathrm{~mm}$. Further, the primary measurement results were processed and the specific volume $v$ depended on the temperature Tc.

By extrapolation, the dependence $v(T)$ in the temperature range in which the polymer is in a fluid state was calculated. On the basis of the same dependence $v(T)$ in the region of the crystallized state, according to the published method of Tager A. A. [4-5], the glass transition temperature Tc of the polymer was determined. Since the HDPE dilatometric curves were obtained at different cooling rates at the time of crystallization $(\mathrm{J})$, we were able to change the Tc of HDPE over a wide temperature range.

Table 1. The value of $T c$ and $f_{c}$ of HDPE samples obtained at different cooling rates at the time of crystallization $(J)$.

\begin{tabular}{llll}
\hline $\mathbf{N N}$ & $\boldsymbol{\gamma}$ & $\mathbf{T}_{\mathbf{c}}$ & $\mathbf{f}_{\mathbf{c}}$ \\
$\mathbf{p} / \mathbf{p}$ & $\mathbf{d e g} / \mathbf{m i n}$ & ${ }^{\mathbf{}^{K}}$ & 0,0256 \\
2 & 0,0056 & 167 & 0,0254 \\
2 & 0,0083 & 184 & 0,0252 \\
3 & 0,0333 & 237 & 0,0248 \\
4 & 0,1 & 257 & 0,0254 \\
5 & 0,2 & 273 & 0,0251 \\
6 & 1,0 & 289 & 0,0257 \\
7 & 3,1 & 301 & 0,0255 \\
8 & 295,0 & 335 & \\
\hline
\end{tabular}

Measurement of the rheological characteristics in a fluid state was carried out using a capillary viscometer according to the adopted method [6] in a wide range of shear strain rates, $\gamma=\square 10 \rrbracket \wedge(-1)-10 \rrbracket \wedge 3$ sec- 1 , shear stresses $\tau=$ $\left[10 \rrbracket \wedge 4-2 \square 10 \square \wedge 6\right.$ dyne $/ \mathrm{cm}^{2}$ and temperatures of $135-300{ }^{\circ} \mathrm{C}$. The melt flow of polyethylene was studied in a capillary with $1 / \mathrm{d}$ equal to 16 and 32 . For this $\tau$, the corresponding value was determined by the formula $\gamma^{\cdot}=\gamma^{-}$. $(3+\mathrm{n})$. where $\gamma=\mathrm{Q} /$ Пг3, and $\mathrm{n}=\mathrm{d}(\lg \gamma) / \mathrm{d}(\lg \tau)$.

The highest Newtonian melt viscosity, $\eta n b$, was obtained by extrapolating the experimental dependence of lgๆnb from $\tau$ to the zero value of $\tau$. And then build a temperature dependence.
It was previously shown [7] that when molding samples from HDPE with different cooling rates at the time of their crystallization, a polymer structure is formed, which differ sharply in density, degree of crystallinity and relaxation properties. This results in the processing of HDPE to produce articles with properties that strongly depend on the molding conditions. The author and his collaborators, using the method of reduced parameters [6, 7], obtained general regularities for the change in the most important physical and mechanical properties of HDPE.

\subsection{Determination of the Manifestation of the \\ Characteristic Physical Properties of Polyethylene}

It is known that the most important kinetic characteristic of the $\neg$ indicators, reflecting their structural features and determining the manifestation of characteristic physical properties, is the glass transition temperature Tc (Table 1). As can be seen from the data we obtained (Table 1), the value of $\mathrm{Tg}$ for HDPE varies greatly depending on the cooling rate of crystallized samples. This fact is a consequence of the formation of structures of HDPE samples, characterized by different degrees of loosening and ordering. At the same time, polymer samples differ in the magnitude of the "free" volume and the temperature dependence of the "free" volume. Therefore, the eight HDPE samples studied, characterized by the same average molecular weight $\mathrm{Mw}$, molecular weight distribution and melt flow rate, depending on the cooling rate, have dilatommetric characteristics approaching the dependence $v(\mathrm{~T})$ either for completely amorphous state, or for an ideal crystalline state.

Thus, at any given temperature $\mathrm{T}$, we have samples of HDPE that differ sharply in their most important structural characteristics: different ratios of "occupied" and "free" volumes, different ratios of amorphous and crystalline regions, different relaxation times of kinetic units of the structure, various density, viscosity, etc.

\section{Result}

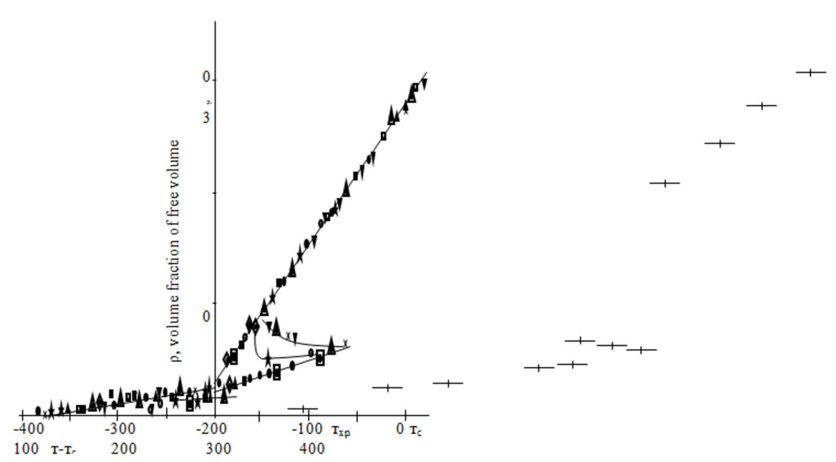

Figure 1. Dependence of the volume fraction of free"volume $(f)$ on the reduced temperature $(T-T c)$ for different samples of PED obtained at different crystallization rates (temperature-invariant characteristic of the volume fraction of free"volume of linear polyethylene).

However, apparently, all these physical characteristics should be proportional to [8] the difference T-Tc. To prove 
this position, the values of $v(T)$ at different $T$ for all eight HDPE samples were processed taking into account the concept of "free" volume and are presented as a dependence of the volume fraction of the "free" volume of polymer samples $\mathrm{f}=\left(\mathrm{v}_{-} \mathrm{T}-\mathrm{v}_{-}(\mathrm{t}=0)\right) \mathrm{v}_{-}(\mathrm{t}=0)$ from the reduced temperature $T \_n(T-T c)$. This dependence of $f$ on $(T-T c)$ is shown in Figure 1. As can be seen from Figure 1, at T-Tc, the value of $\mathrm{f}$ for all samples of polyethylene cooled at different speeds is located practically at one point, the ordinate of which is equal to the universal value $\mathrm{fc}=0,025 \pm 0,0006$.

Further, depending on the values of $\mathrm{T}-\mathrm{Tc}$, all experimental data were located on two branches: the upper branch is a dependence of $f$ on $(\mathrm{T}-\mathrm{Tc})$ for the polymer flowable state, the lower one for the crystallized (solid) state. At the same time, the difference between the volume thermal expansion coefficients of the "free" volume of polyethylene for these states is

$$
\begin{gathered}
d_{2}=T>T_{\text {крист }}-(d f) T<T_{\text {крист }}=6,3 \cdot 10^{-4}-1,5 \\
10^{-4}=4,8 \cdot 10^{-4}\left(\text { deg }^{-1}\right)
\end{gathered}
$$

which agrees well with the constant universal value for many linear polymers [87-89].

At $\mathrm{T}<\mathrm{TC}$, all experimental data are located on almost one dependence, the inflection point of which corresponds to the temperature of brittleness Txp, equal for HDPE

$$
\mathrm{T}_{\mathrm{XP}}=\mathrm{T}_{\mathrm{C}^{-}} 77^{\circ}
$$

The brittleness temperature corresponds to $\mathrm{fkp}=0.014$.

Thus, the dependence off on T-Tc is the temperatureinvariant characteristic of the "free" volume of the polymer. The existence of this dependence allows determining the value of the specific volume or density of the polymer (as well as the values of the specific "free" volume and f values) at any temperature and at any cooling rate $\mathrm{J}$, if only the dependence of $\mathrm{Tc}$ on $\mathrm{J}$ is known and the value of the specific volume at one any temperature $t$.

On the other hand, this universal dependence confirms the fact that any physical property of polyethylene (and of polymers in general) is proportional to the reduced temperature $(\mathrm{T}-\mathrm{Tc})$.

To construct the temperature-invariant characteristics of any physical properties of polymers by the method of the above parameters [8-14], a dimensionless displacement parameter is usually used.

$$
\alpha_{T}=\frac{\eta \cdot \rho_{0} \cdot T_{0}}{\eta_{0} \cdot \rho T}=\frac{Q}{Q_{0}}
$$

where $\mathrm{T}$ is the temperature of reduction;

$\eta_{0}, \rho_{0}, Q_{0}, \eta, \rho, Q$ - viscosity, density and generalized relaxation time, respectively, at a temperature of reduction $\mathrm{T} 0$ and any other temperature $\mathrm{T}$.

The works of M. Williams [8], P. Landel, D. Ferry [9], A. Tobolsky [10], Foy T. V., Flory R. J [14], Doolittle A. N [15] it was shown that $\alpha \mathrm{T}$ is a definite function $(\mathrm{T}-\mathrm{Tc})$ :

$$
\lg \alpha_{T}=\frac{1}{2,303 f c}\left(T-T_{c}\right) /\left(\frac{f_{c}}{\alpha_{2}}+T-T_{c}\right)
$$

For the HDPE samples that we studied, the dependence of $\lg \alpha \_\mathrm{T}$ on $(\mathrm{T}-\mathrm{Tc})$ is shown in Figure 2. As can be seen from figure 2 , this dependence is indeed temperature-invariant for all the samples studied. Knowing the value of ss., It is possible at any temperature $\mathrm{T}$ to determine the physical size of the polymer of interest to us, if the value of this value is known at any temperature.

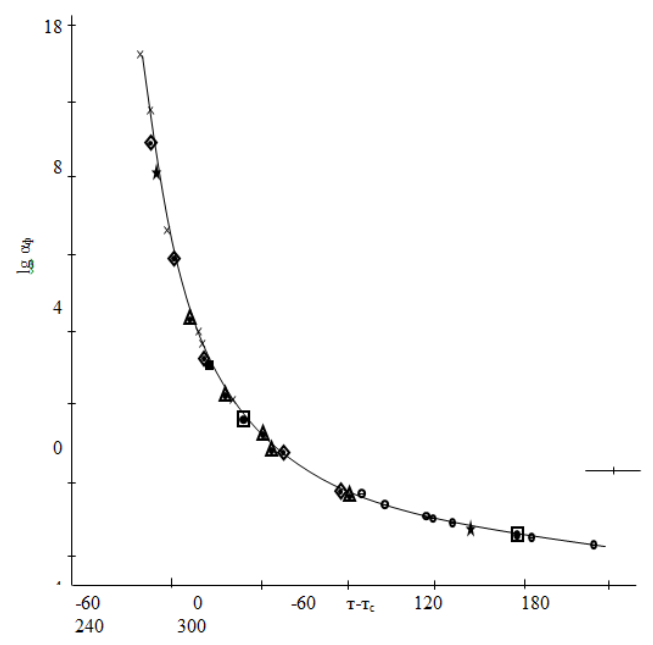

Figure 2. The dependence of the shift parameter $\alpha T$ on the reduced temperature $\left(T-T_{0}\right)$ for linear PE samples.

The component of the parameter is the relation $\rho_{0} T_{0} / \rho T /$ $\rho T$ equal to $\left(\eta_{0} / \eta\right) \alpha_{T}$ or equal to $\eta_{0} Q / \eta Q$. The significance of this important component and its temperature dependence for many polymers is not known, in particular, for HDPE such data are absent in the literature. Many researchers usually take the value of $\rho_{0} T_{0} / \rho T$ equal to 1 .

The dependence of $\rho_{0} T_{0} / \rho T$ on the reduced temperature $\left(\mathrm{T}-\mathrm{T}_{0}\right.$ ) for HDPE samples is shown in Figure 3. As can be seen from Figure 3, depending on the temperature of the reduction $\mathrm{T}$, the nature of the dependence of $\rho_{0} T_{0} / \rho T$ on $(\mathrm{T}-$ $\mathrm{T}_{0}$ ) changes dramatically, the smaller $\mathrm{T}_{0}$, i.e., the closer $\mathrm{T}_{0}$ is to $\mathrm{Tc}$, the more $\rho_{0} T_{0} / \rho T \mathrm{~T}$ differs from 1 (curves $9-1$ in Figure 1); the greater the temperature of the experiment $\mathrm{T}$, at which $\rho_{0} T_{0} / \rho T$ is estimated, the more $\rho_{0} T_{0} / \rho T$ differs from 1. The dotted lines in figure 2. The isotherms of $\rho_{0} T_{0} / \rho T$ versus $\left(\mathrm{T}-\mathrm{T}_{0}\right)$ are shown for various $\mathrm{T}=$ Const.

\section{Discusion}

Thus, even in a fluid state of the polymer, when $\mathrm{T}>\mathrm{Tm}$ (curve 9 in Figure. 3, on which data are plotted at temperatures from $423^{\circ} \mathrm{K}$ to $573^{\circ} \mathrm{K}$, the equilibrium melting point of HDPE is $\mathrm{Tpl}=413^{\circ} \mathrm{K}$ ) differs from 1 by value to 0.18 (i.e. by $18 \%$ ) depending on $\mathrm{T}$. The maximum deviation $\rho_{0} T_{0} / \rho T$ from 1 , equal to 0.6 (i.e. $60 \%$ ), can be at $\mathrm{T}=573^{\circ} \mathrm{K}$, if $\mathrm{T} 0$ is taken to be equal to the equilibrium glass transition temperature $\mathrm{Tc}=167^{\circ} \mathrm{K}$. This feature of $\rho_{0} T_{0} / \rho T$ and its temperature dependence for HDPE is related to the high crystallinity of this linear polymer. 


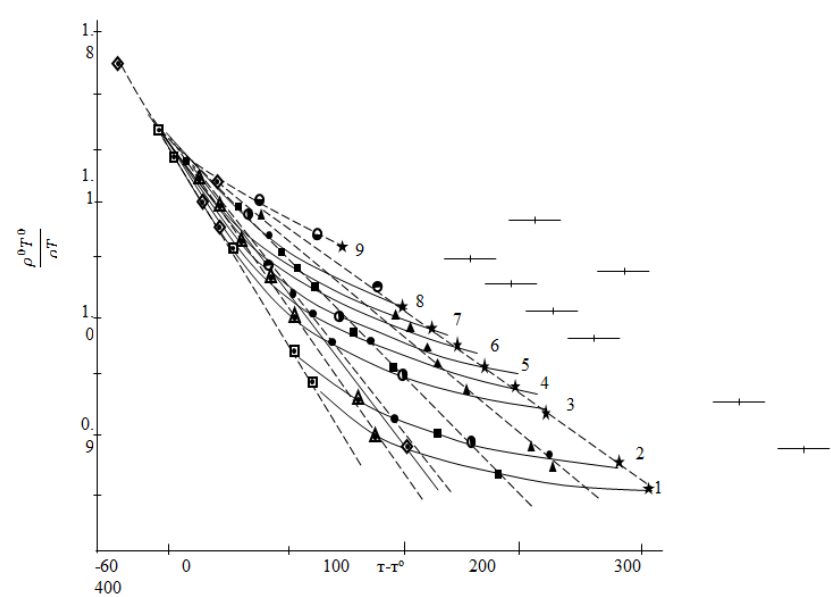

Figure 3. The dependence of $\rho_{0} T_{0} / \rho T$ (relative reduced density of the polymer) on the reduced temperature $\left(T-T_{0}\right)$.

An important component of the value of at is also the ratio of viscosities at the temperature of reduction $\mathrm{T}_{0}$ and any other temperature $\mathrm{T}$, that is, $\eta_{0} / \eta$ (if Tc is taken as the temperature of reduction, $\eta T c$ is 1013 poise [10-34]). The dependence of the highest Newtonian viscosity of the melt $\eta n b$ for the investigated HDPE is shown in Figure 4. As can be seen from figure 4 , in the region of temperature $423^{\circ} \mathrm{K}$, i.e., long before reaching the equilibrium melting temperature $\left(413^{\circ}\right.$ $\mathrm{K})$ and the apparent melting point $\left(405^{\circ} \mathrm{K}\right)$, viscosity increases especially sharply with decreasing temperature. In this case, the magnitude of the apparent heat of activation of the flow increases sharply: from a value of 5-7 kcal / mol to a value of $12.6 \mathrm{kcal} / \mathrm{mol}$. This circumstance is the result of the ordering of the polymer structure in the temperature region near Tm, which leads to an increase in the intermolecular interaction due to the formation in the melt of structures that are extremely prepared for crystallization. This state can be characterized as a state of flow of melt structures, with kinetic units apparently being oriented aggregates of segments of macromolecules moving in the melt as whole units [35-39].

The generalization of the obtained experimental results of rheological and dilatometric studies was performed using the well-known VLF equation [17]. To this end, at different temperatures (from $413^{\circ} \mathrm{K}$ to $573{ }^{\circ} \mathrm{K}$ ), the dependence of the reduced parameter $\mathrm{C}=\left(\lg \eta \_\mathrm{T} / \eta_{-} \mathrm{c}-\operatorname{lgM} \_\mathrm{w}^{\wedge}(-3.4)+\right.$ $\lg \alpha \mathrm{T})$ was studied, and the reduced parameter $\left(\lg \mathrm{M}_{-} \mathrm{w}^{\wedge}(-\right.$ $\left.3,4)+\lg \alpha \_T\right)$ for the studied HDPE samples, characterized by a medium viscous molecular mass $\mathrm{Mw}=8.3 \mathrm{x} 104$, (Figure 5) The invariance of experimental data regarding temperature over the entire investigated range shows that the equation is generalized a characteristic of the temperature dependence of the most important physical properties of HDPE and, apparently, of all linear polymers.

$$
\frac{\eta_{T}}{\eta_{T c}}-\lg M w^{-3,4}+\lg \alpha_{T}=C
$$

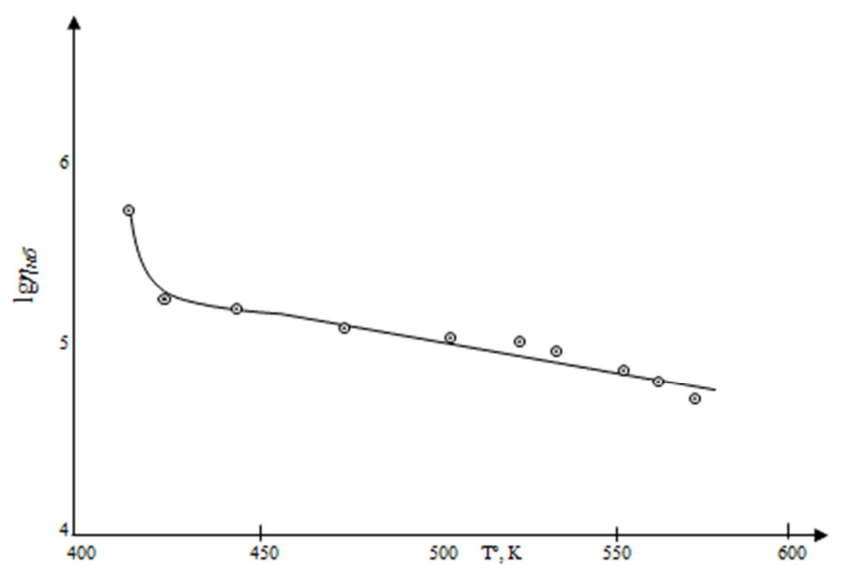

Figure 4. Dependence of the greatest Newtonian viscosity of the melt, $\eta n b$, on temperature T for PESD.

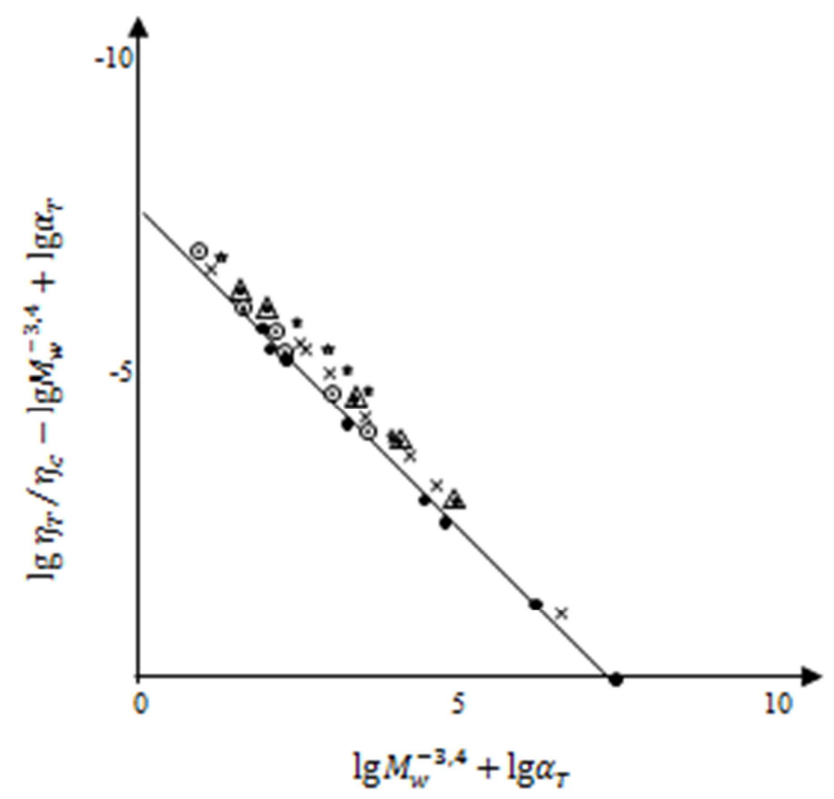

Figure 5. The dependence of the reduced parameter $\lg \eta_{T} / \eta_{c}-\lg M_{w}^{-3,4}+$ $\left.\lg \alpha_{T}\right)$ on the reduced parameter $\left(\lg M_{w}^{-3,4}+\lg \alpha_{T}\right)$.

\section{Conclusion}

In this work, we studied the generalization of the temperature dependence of the physical properties of highstrength polyethylene using the method of given parameters

According to the dependence of the above parameter and the highest Newtonian viscosity of the melt, ๆnb depends on the temperature.

Based on the research, it has been established that the invariance of experimental data on the temperature in the entire investigated range of the most important physical properties of HDPE depends on temperature and viscosity average molecular weight.

\section{Recommendations}

The shown difference of high-strength polyethylene from other polyethylenes should be taken into account during 
processing and operation of materials obtained from them.

\section{References}

[1] Buniyat-zade A. A. Sagalaev G. V., Ismailov T. M., Svyatodukhov B. P. Plastics, 1972, 12, p. 44-46.

[2] Fisher. Chemistry and technology of polymers. 10, 119, 1965.

[3] Mandelykern L. Crystallization of polymers. Per. with English, ed. S. Ya. Frenkel. Publishing house "Chemistry", M.-L., 1966.

[4] Konyukh I. V., Zabugina M. P., Vinogradov G. V. Factory laboratory. I, 123.1965.

[5] Tager A. A. Physicochemistry of Polymers, ed. Pth, ed. "Chemistry", M. 1968.

[6] Vinogradov G. V., Prozorovskaya N. V. Plastic masses. 5, 50, 1964, 2, 36, 1966.

[7] Buniyat-zade A. A., Sagalaev G. V., Ismayilov T. M., Svyatodukhov B. P. Plastic masses, 12, 1972.

[8] Williams M. Z., Zandel R. F., Ferry J. D. J. Amer. Chem. Soc. 77, 3701, 1955.

[9] J. Ferry. Viscoelastic properties of polymers. Per. with English, ed. V. E. Gulya. Ed. IL, M., 1963.

[10] Tobolsky A. J. Polymer Sci Part C, 9, 157, 1965.

[11] Vinogradov G. V., Malkin A. Ya., Prozorovskaya N. V.

[12] Doolittle A. N., Appl Phys. 22, 1471, 1951, 23, 236, 1952, 28, 901.1957.

[13] Serenko O. A., Goncharuk G. P. et al. / Effect of temperature on the deformation behavior of a composite based on polypropylene and rubber particles // High Molecular Compounds.-2007.-No. 1.-P. 71-78.

[14] Derikov I. Ya., Kutergina I. Yu. et al. / Stable nonequilibrium composites based on liquid crystalline polymers and cadmium selenide nanoparticles // High Molecular Compounds. 2014. No. 4, pp. 408-418.

[15] Zaikin AE, Bobrov GB / Compatibilization of mixtures of incompatible polymers by filling // High-molecular compounds.-2012.-№8.-p. 1275-1282.

[16] Kuleznev V. N., Surikov P. V. // Phase equilibria in threecomponent polymer blends / High-molecular compounds.2012.-No. 11.-p. 1602-1609.

[17] Chalykh A. E., Gerasimov V. K., Mikhailov Yu. M. Diagrams of the phase state of polymer systems. M.: Janus, 1998.

[18] Mulder M. // Basic Principles of Membrane Technology. Dordrecht: Kluwer, 1996.

[19] Belov N. A., Safronov A. P., Yu. P. Yampolsky // Reverse gas chromatography and thermodynamics of sorption in polymers. / High-molecular compounds.-2012.-No. 11.-p. 1631-1647.
[20] Bundjali B., Yudistira I., JAriah B, Sukria L. // Study on properties of Polymer Blends from Polypropylene with Polycaprolactone and their Biodegradability / Polymer Journal, -2007 - Vol. 39, No. 12.-pp. 1337-1344.

[21] Ermilova EA, Sizova AA, Ilyicheva NN, Pleshakov DV. // Investigation of the thermodynamic compatibility of a threecomponent mixture of nitramines with a copolymer of methyl methacrylate and methacrylic acid. / Advances in chemistry and chemical technology. 2014 - No. 2.-p. 65-67.

[22] Rijhikova I. G., Volkov A. M., et all. Modification feature of binary mixtures PP / SKEP by the system of organic peroxidepolyfunctional vinyl monomer in the reaction extrusion process. Plastic masses, 8, 2013, p. 40-45.

[23] Murtazina L. I., Garifullin A. R., Nikultsev I. A., et all. Influence of plastificators on the property of unhardened hermetics on the basis of ethylene-propylendiene rubber. Engineer-chemist's encyclopedia, No. 8, 2014, pp. 31-35.

[24] Kirsh I. A., Pomogova D. A. Study of the properties of secondary polymer materials based on polypropylene and polyethyleneterephtalat, obtained in the influence of ultrasonic vibrations on the polymer melts. - Moscow, Plastic masses, 2012, No. 1, pp. 48-51.

[25] Kurbanova N. I. Heatelastolastics based on polypropylene and tri-etylene-propylene copolymer. Azerbaijan chemistry, - No. 1, - 2013, - P. 57-59. -2008 - No. 4.-p. 69-72.

[26] Turaev ER, Beknazarov Kh. S, Akhmedov UK, Jalilov AT. // Interphase interactions of three-phase polypropylene composite materials. / Universum. Technical sciences./- 2018№12.- p. 57.

[27] Shastin D. A., Wolfson S. I., Makarov T. V.// Influence of modification of triple ethylene-propylene rubber on the physicomechanical properties of rubbers./ Vestnik of Kazan Technological University.-2010-№4.-p. 5-7.

[28] Ryzhikova I. G., Volkov A. M., Bauman N. A., Kazakov Yu. M., Wolfson S. I. // Influence of the concentration of components of the modifying system peroxide / TMPTA and the Mooney viscosity of rubber SKEPT on the balance of yield and impact resistance SKEPT master-batches in a polypropylene matrix. / Bulletin of the Technological University-2015-No. 4.-from 148-150.

[29] Ryzhikova I. G., Volkov A. M., Bauman N. A., Kazakov Yu. M., Wolfson C. B. - 2015. - No. 4.-p. 134-137.

[30] Nurmeeva EK. // Production and scope of ethylene-propylene rubbers SKEPT / Bulletin of Kazan Technological University.2012-p. 129-131.

[31] Prospects for the development of production of ethylenepropylene rubber // Production and use of elastomers. - 1998. No. 1. - S.53-54.

[32] Klyuchnikov I. O., Klyuchnikov O. R., Stoyanov O. V. // Bulletin of Kazan Technological University. 